\title{
Vaginal laser for overactive bladder syndrome
}

\author{
loannis Charalampous ${ }^{1}$ - Visha K. Tailor ${ }^{2} \cdot$ Alex Digesu $^{2}$
}

Received: 7 April 2020 / Accepted: 16 April 2020 / Published online: 12 May 2020

(C) The Author(s) 2020

\begin{abstract}
Overactive bladder syndrome $(\mathrm{OAB})$ is defined as urinary urgency, usually with urinary frequency and nocturia, with or without urge urinary incontinence. The prevalence of $\mathrm{OAB}$ in adult women ranges between $11 \%$ and $42 \%$, is particularly common in elderly people, and can overlap with the genitourinary syndrome of menopause (GSM). There is a wide approach to the treatment of symptoms, often in a stepwise fashion, including lifestyle changes, bladder retraining and pelvic floor muscle rehabilitation, drug therapy, intra-vesical botulinum toxin injections or neuromodulation. Recently, vaginal laser therapy has been proposed as an emerging minimal invasive effective treatment option for women with OAB. We explore this further.
\end{abstract}

Keywords Overactive bladder syndrome $\cdot$ Vaginal laser

Overactive bladder syndrome $(\mathrm{OAB})$ is defined as urinary urgency, usually with urinary frequency and nocturia, with or without urge urinary incontinence. The prevalence of $\mathrm{OAB}$ in adult women ranges between $11 \%$ and $42 \%$, and is particularly common with age, overlapping with the genitourinary syndrome of menopause (GSM). There is a wide approach to the treatment of symptoms, often in a stepwise fashion, including lifestyle changes, bladder retraining and pelvic floor muscle rehabilitation, drug therapy, intra-vesical botulinum toxin injections or neuromodulation. Recently vaginal laser therapy has been proposed as an emerging minimal invasive effective treatment option for women with $\mathrm{OAB}$ [1-6].

Fractional microablative $\mathrm{CO}_{2}$ and Er:YAG laser are the two most commonly used intra-vaginal therapy methods [7-9]. Vaginal laser aims to induce collagen remodelling and neocollagenesis processes. Histopathological studies have described: an increase in proliferation of the intermediate and shedding superficial cells as well as of the underlying connective tissue; an increase in the vaginal epithelium thickness; an

Visha K. Tailor

vishatailor@nhs.net

1 Medical School, University of Nicosia, Nicosia, Cyprus

2 Department of Urogynaecology, St Marys Hospital, Imperial College NHS Trust, 4th Floor, Mary Stanford Building, London W2 1NY, UK increase in the fibroblast growth factor and transforming growth factor beta 1 (TGF- $\beta 1$ ) that have been advocated as responsible for laser-induced neocollagenesis and neoangiogenesis [3]. However, how this laser-induced tissue effect translates into an improvement of $\mathrm{OAB}$ symptoms has never been explained and it is currently still questionable and unknown.

Several authors to date have explored the effectiveness of vaginal lasers to treat GSM, with few studies focusing only on outcomes in women with OAB symptoms. Perino et al. carried out a pilot study treating 30 post-menopausal women with $\mathrm{OAB}$ symptoms with three sessions of vaginal $\mathrm{CO}_{2}$ fractional laser over least 30 days. At 30 days, the mean OAB-q-SF scores were reduced from 18 to 8 . A total of 9 women with $\mathrm{OAB}$-wet also demonstrated an improvement in the incontinence episodes [9]. The absence of a randomised or a control group, the small sample size, as well as the lack of long-term follow-up, represent the main limitations of this study.

Aguiar et al. conducted a similar study on 72 postmenopausal women randomised to receive either vaginal lubrication, vaginal oestrogen or three treatments of vaginal $\mathrm{CO}_{2}$ fractional laser 30-45 days apart. In this study, up to $81 \%$ of the women experienced urge urinary incontinence. Two of the 24 women undergoing vaginal laser treatment were lost to follow-up at 14 weeks. A small but statistically significant improvement in ICIQ-OAB scores was described. No adverse effects were reported during the study period [10]. The results of Aguiar et al. show a small but statistically 
significant difference between the intravaginal fractional $\mathrm{CO}_{2}$ laser and topical oestrogen groups for treating OAB symptoms related to GSM [10]. Once more the sample size was too small to draw any long-term conclusions for the efficacy of vaginal laser use for the treatment of OAB symptoms.

A similar study was carried out in 2015. In a pilot study women were treated with two sessions of Er:YAG laser treatment 4 weeks apart. A total of $60 \%$ of the cohort was satisfied with the treatment and reported an improvement in $\mathrm{OAB}$ symptoms at 3 months. However, the benefits were not sustained at 12 months. The authors also described a temporary improvement in sexual function. Minor side effects such as vaginal discharge or spotting lasting a few days after treatment were reported [11]. This study also had limitations such as the retrospective design, the small case series and the lack of face-to-face visit at 12 months' follow-up that is important in our opinion in order to objectively assess the laser-induced effects on the vaginal tissues. Furthermore, the subjective questionnaires at 12 months after laser therapy do not provide adequate evidence to make a strong case for the use of vaginal laser treatment.

Finally, Okui also compared the efficacy of Er:YAG laser treatment and fesoterodine and mirabegron at treating $\mathrm{OAB}$ symptoms in 150 post-menopausal women. Women received once-monthly laser treatment for 3 months. In this study, all three groups reported a significant improvement in OAB Symptom Scores (OABSS) at 12 months. Only 1 patient did not respond to vaginal laser treatment. No adverse events were reported in the laser group [12]. Limitations include being a single-centre, single-operator study and the absence of a placebo arm.

In summary, the current published studies on vaginal laser therapy for women with $\mathrm{OAB}$ symptoms present a questionable therapeutic response. They have a small study population, are limited to single centres, with no long-term follow-up or inconsistent long-term results. Finally, and more importantly, to our knowledge, no sham randomized control studies have been carried out to date. Therefore, the current evidence supporting the use of vaginal laser treatment for $\mathrm{OAB}$ is still weak and limited. Although adverse events are not reported by these studies, there are reports of dyspareunia and vaginal scarring in the literature. The laser-induced risks of loss of surgical tissue planes if surgical intervention is subsequently required, as well as the possible susceptibility to infection or viruses such as the human papilloma virus, have also been reported $[2,3]$.

In view of the lack of robust scientific evidence, to date, vaginal laser therapy should be considered an unproven option for OAB symptoms related to GSM [8-12]. In addition, promotion of this approach for the treatment of exclusively $\mathrm{OAB}$ syndrome is not advised without further research investigating the efficacy and safety of this potentially long-term treatment modality. This would be best served as a well-planned, sham controlled, randomised controlled study with a long-term follow-up and robust evaluation methods.

Contributions I. Charalampous: manuscript writing, data collection; V. Tailor: manuscript writing, data collection, editing; A. Digesu: manuscript editing

\section{Compliance with ethical standards}

\section{Conflicts of interest None.}

Open Access This article is licensed under a Creative Commons Attribution 4.0 International License, which permits use, sharing, adaptation, distribution and reproduction in any medium or format, as long as you give appropriate credit to the original author(s) and the source, provide a link to the Creative Commons licence, and indicate if changes were made. The images or other third party material in this article are included in the article's Creative Commons licence, unless indicated otherwise in a credit line to the material. If material is not included in the article's Creative Commons licence and your intended use is not permitted by statutory regulation or exceeds the permitted use, you will need to obtain permission directly from the copyright holder. To view a copy of this licence, visit http://creativecommons.org/licenses/by/4.0/.

\section{References}

1. Hsu FC, Weeks CE, Selph SS, Blazina I, Holmes RS, McDonagh MS. Updating the evidence on drugs to treat overactive bladder: a systematic review. Int Urogynecol J. 2019;30(10):1603-17. https:// doi.org/10.1007/s00192-019-04022-8.

2. Bhide AA, Khullar V, Swift S, Digesu GA. The use of laser in urogynaecology. Int Urogynecol J. 2019;30(5):683-92. https:// doi.org/10.1007/s00192-018-3844-7.

3. Shobeiri SA, Kerkhof MH, Minassian VA, Bazi T. IUGA Research and Development Committee. IUGA committee opinion: laserbased vaginal devices for treatment of stress urinary incontinence, genitourinary syndrome of menopause, and vaginal laxity. Int Urogynecol J. 2019;30(3):371-6. https://doi.org/10.1007/s00192018-3830-0.

4. Tranoulis A, Georgiou D, Michala L. Laser treatment for the management of genitourinary syndrome of menopause after breast cancer. Hope or hype? Int Urogynecol J. 2019;30(11):1879-86. https:// doi.org/10.1007/s00192-019-04051-3.

5. Garcia B, Pardo J. Academic cosmetic gynecology and energybased therapies: ambiguities, explorations, and FDA advisories. Int Urogynecol J. 2019;30(1):1-2. https://doi.org/10.1007/s00192018-3812-2.

6. Dabaja H, Lauterbach R, Matanes E, Gruenwald I, Lowenstein L. The safety and efficacy of $\mathrm{CO}_{2}$ laser in the treatment of stress urinary incontinence. Int Urogynecol J 2019;30(10):1603-17. https://doi.org/10.1007/s00192-019-04204-4.

7. Kuszka A, Gamper M, Walser C, Kociszewski J, Viereck V. Erbium:YAG laser treatment of female stress urinary incontinence: midterm data. Int Urogynecol J 2019. https://doi.org/10.1007/ s00192-019-04148-9.

8. González Isaza P, Jaguszewska K, Cardona JL, Lukaszuk M. Longterm effect of thermoablative fractional $\mathrm{CO}_{2}$ laser treatment as a novel approach to urinary incontinence management in women with genitourinary syndrome of menopause. Int Urogynecol J. 2018;29(2):211-5. https://doi.org/10.1007/s00192-017-3352-1. 
9. Perino A, Cucinella G, Gugliotta G, Saitta S, Polito S, Adile B, et al. Is vaginal fractional $\mathrm{CO} 2$ laser treatment effective in improving overactive bladder symptoms in post-menopausal patients? Preliminary results. Eur Rev Med Pharmacol Sci. 2016;20(12): 2491-7.

10. Aguiar LB, Politano CA, Costa-Paiva L, Juliato CRT. Efficacy of fractional $\mathrm{CO}_{2}$ laser, Promestriene, and vaginal lubricant in the treatment of urinary symptoms in postmenopausal women: a randomized clinical trial. Lasers Surg Med 2020. https://doi.org/10. 1002/lsm.23220.

11. Lin YH, Hsieh WC, Huang L, Liang CC. Effect of non-laser treatment on overactive bladder symptoms, urinary incontinence and sexual function in women with urodynamic stress incontinence. Taiwan J Obstet Gynecol. 2017;56(6):815-20. https://doi.org/10. 1016/j.tjog.2017.10.020.

12. Okui N. Efficacy and safety of non-ablative vaginal erbium: YAG laser treatment as a novel surgical treatment for overactive bladder syndrome: comparison with anticholinergics and $\beta 3$-adrenoceptor agonists. World J Urol. 2019;37(11):2459-66. https://doi.org/10. 1007/s00345-019-02644-7.

Publisher's note Springer Nature remains neutral with regard to jurisdictional claims in published maps and institutional affiliations. 